\title{
Proteomic approach to identify candidate effector molecules during the in vitro immune exclusion of infective Teladorsagia circumcincta in the abomasum of sheep
}

\author{
Spiridoula Athanasiadou ${ }^{1,2 *}$, Alan PeMberton ${ }^{3}$, Frank JACKSON $^{2}$, \\ Neil INGLis ${ }^{4}$, Hugh R.P. Miller ${ }^{3}$, Frank THÉVENOD ${ }^{5}$, Annie MACKELlaR ${ }^{2}$, \\ John F. HUNTLEY ${ }^{2}$ \\ ${ }^{1}$ Animal Nutrition and Health, Scottish Agricultural College, Bush Estate, Penicuik, EH26 0PH, Scotland, UK \\ ${ }^{2}$ Division of Parasitology, Moredun Research Institute, Pentlands Science Park, Bush Loan, \\ Penicuik, EH26 0PZ, Scotland, UK \\ ${ }^{3}$ Division of Veterinary Clinical Studies, University of Edinburgh, Easter Bush Veterinary Centre, \\ Roslin, EH25 9RG, Scotland, UK \\ ${ }^{4}$ Moredun Proteomics Facility, Moredun Research Institute, Pentlands Science Park, Bush Loan, \\ Penicuik, EH26 0PZ, Scotland, UK \\ ${ }^{5}$ Department of Physiology and Pathophysiology, University of Witten/Herdecke, Stockumer Str. 12, \\ D-58453 Witten, Germany
}

(Received 26 March 2008; accepted 13 August 2008)

\begin{abstract}
In the present study we have employed an in vitro organ challenge model to study the post-challenge responses in parasite naïve and immune gastric tissue of sheep, in an attempt to identify the host derived factors involved in immune exclusion of Teladorsagia circumcincta larvae. Proteins present in the epithelial cells and mucus from ovine abomasa following parasite challenge in previously naïve and immune animals were analysed through Matrix Assisted Laser Desorption/Ionization-Time of Flight (MALDI-Tof)-MS and shotgun proteomics. MALDI-ToF analysis of epithelial cell lysates revealed that a number of proteins identified were differentially expressed in naïve and immune cells. These included intelectin and lysozymes, which were present at higher levels in epithelial cell lysates derived from immune samples. A large number of proteins were identified in the mucosal wash from immune tissue which were not present in the mucosal wash of the naïve tissue. Some of these proteins were present in washes of immune tissue prior to the parasite challenge including immunoglobulin A, galectin 14 and 15 and sheep mast cell protease 1 . However, other proteins, such as calcium activated chloride channel and intelectin were only detected in the washings from the challenged tissue. The latter may be related to an enhanced mucus release, which may result in entrapment of infective larvae and thus reduced establishment in tissue that has been previously challenged with the parasite. In conclusion, several proteins have been identified which may be involved, either directly or indirectly, in the exclusion and immune elimination of incoming infective larvae. In the present study, the usefulness of the in vitro model has been confirmed, and the global proteomic approach has identified proteins that had not previously been associated with parasite exclusion from abomasal mucosa, such as the calcium activated chloride channel.
\end{abstract}

immunity / mucus / proteomics / sheep / Teladorsagia circumcincta

\footnotetext{
* Corresponding author: spiridoula.athanasiadou@sac.ac.uk 


\section{INTRODUCTION}

Host immunity to gastrointestinal nematodes is expressed in many ways and is targeted against adult and larval stages of nematode parasites. Resistance against adult nematodes can be manifested as reduction in fecundity of females, changes in the morphology and or the expulsion of parasites whereas resistance against larval stages of nematodes is manifested as arrested development, reduced establishment and exclusion of immature nematodes [1,21]. The mechanisms that are involved in these immune processes are complex, and probably involve both acquired and innate immune factors including antibodies, inflammatory cell mediators, changes in mucus quality and associated factors. However, despite the plethora of studies to define these immune mechanisms, the final effector molecules which elicit parasite expulsion remain unknown.

The phenomenon of immune exclusion of infective larvae in primed hosts is commonly observed in ruminant gastrointestinal nematode infections. Miller et al. [20] reported that immune sheep prevented the establishment and expelled the majority of Haemonchus contortus L3 within $48 \mathrm{~h}$ post infection, with more than $95 \%$ of the larval challenge failing to establish in the immune tissue. Similar expulsion rates were observed in immune sheep infected with a Trichostrongylus colubriformis larval challenge [17]. An in vitro method has recently been developed, in which abomasal tissue explants were challenged with exsheathed Teladorsagia (T.) circumcincta to investigate this phenomenon of immune exclusion of immature larvae [13]. In this study it was shown that: (i) in vitro establishment rates of L3 were similar to those reported in vivo, in naïve and immune tissue; and (ii) larval establishment was higher in previously naïve than in immune tissue. The epithelial tissue retained its histological integrity during the short term (up to $3 \mathrm{~h}$ ) incubation, indicating that the exclusion of applied larvae to immune tissue was due to the functional activity of pre-existing or newly secreted factors.
In the present study we have therefore employed this in vitro model to study the induction of post-challenge responses in previously naïve and immune gastric tissue of sheep, in an attempt to identify the host derived factors involved in larval immune exclusion. Tryptic fragments of proteins present in the mucus from ovine abomasa were analysed through liquid chromatography electrospray ionisation (LC-ESI) in combination with tandem mass spectrometry (MS/MS), which enabled the simultaneous detection of multiple proteins [2], whereas those isolated from the epithelial cells of the gastric mucosa were individually isolated from two dimensional gels and identified with Matrix Assisted Laser Desorption/Ionization-Time Of Flight (MALDI-ToF).

\section{MATERIALS AND METHODS}

\subsection{Animals and post mortem collection of abomasa}

Gastric tissue from 6 parasite naïve and 8 immune sheep was used for this study. Naïve sheep were reared indoors under conditions that minimised parasite exposure. All naïve animals were screened for nematode eggs in their faeces and were negative prior to slaughter. The immune animals were ewes that had been exposed to natural parasite challenge, consisting mainly from $T$. circumcincta, grazing normal grass/clover pastures. All immune animals were positive for nematode egg counts (consistently lower than 10 eggs per gram). Sheep were killed by lethal injection (Pentobarbital). The abdomen was opened along the midline to allow the removal of the gastrointestinal tract. Abomasa of sheep were removed immediately from animals, opened and parts of the abomasal folds approximately $2 \times 2 \mathrm{~cm}$ were removed for the in vitro challenge. Abomasal tissue was gently rinsed in saline $(0.85 \%)$ to minimise contamination with abomasal digesta.

\subsection{In vitro model and sample preparation}

This method is a modification of the one described in detail by Jackson et al. [13]. In brief, three tissue sections from abomasal folds measuring approximately $2 \times 2 \mathrm{~cm}$ were challenged with $2500 \mathrm{~L} 3$ of $T$. circumcincta (in $0.5 \mathrm{~mL}$ of water) 
into isolation chambers formed with the barrels of $5 \mathrm{~mL}$ syringes. The tissue sections were surrounded by media consisting of $20 \mathrm{mmol} / \mathrm{L}$ Hepes with $2 \mathrm{~mL}$ phenol red added to $1 \mathrm{~L}$ of sterile water $(\mathrm{pH}$ 7.6). Following the incubation of the tissue sections at $37^{\circ} \mathrm{C}$ in high oxygen environment and darkness for $3 \mathrm{~h}$, the syringe barrels were rinsed with saline, and tissues were washed vigorously by immersing the tissue sections 30 times in $25 \mathrm{~mL}$ of phosphate buffered saline (PBS). Subsequently, instead of progressing with the digestion of the tissue section in $1 \%$ pepsin/ $1 \% \mathrm{HCl}$ solution as described by Jackson et al. [13], tissue sections were then placed into a tube containing $30 \mathrm{~mL}$ of digestion medium consisting of $5 \mathrm{~mL}$ of $1 \%$ Foetal Calf Serum (FCS, Sigma, Irvine, UK), $250 \mu \mathrm{g}$ of gentamycin $(25 \mu \mathrm{g} / \mathrm{mL}$, Sigma), $5 \mathrm{~mL}$ of penicillin/streptomycin $(1 \%)$ and $85 \mu \mathrm{L}$ of each of the enzymes, collagenase $(75 \mathrm{U} / \mathrm{mL}$, Sigma) and dispase I $(20 \mu \mathrm{g} / \mathrm{mL}$, Sigma $)$ in $500 \mathrm{~mL}$ of complete DMEM (D5671, Sigma). The aim of the enzymatic dispersion of the epithelial cells was two-fold: (i) to release the larvae that were closely associated to the gastric mucosa, and (ii) to achieve dispersion of epithelial cells for the proteomic analysis. The enzymatic dispersion was based on the method described by Dziva et al. [4].

Tissue was maintained in the digestion medium for $2 \mathrm{~h}$ and were vigorously rotated at $37^{\circ} \mathrm{C}$.

The percentage of the larval population closely associated with the mucosa was calculated using the standard formula:

$$
\% \text { tissue association }=(\mathrm{DL} / \mathrm{TLP}) \times 100
$$

where DL is the number of larvae recovered from the digested tissue and TPL the total larval population (larvae in the rinse, wash and digest). Student's $t$-test (Microsoft Excel) was used to statistically analyse the percentage of the larval population closely associated with the mucosa in previously immune and naïve tissue.

Mucosal washes were thoroughly mixed and a subsample was removed to count the number of larvae. The remaining material was centrifuged and the pellet, which included nematode larvae, was discarded. The supernatant was freeze dried to increase the concentration of soluble molecules, redissolved in a low volume of water, desalted by gel filtration in distilled water (PD-10, GE HealthCare, Bucks, UK) and further freeze dried. Mucosal wash samples were also prepared from unchallenged controls.
Gradient centrifugation was used to isolate epithelial cells from larvae and cell debris present in the cell suspension following incubation in the digestion medium. For this purpose a layer of the epithelial cell suspension was laid on top of Lymphoprep (Axis Shield Diagnostics, Dundee, UK) and the sample was centrifuged at $1900 \mathrm{~g} \times 15 \mathrm{~min}$. The epithelial cell layer was then removed and subjected to three washes in HSBB, to remove Lymphoprep and other debris. Cells were then assessed for their viability, by staining them with $0.1 \%$ nigrosin. Cytospins (Shandon cytospin 4, Thermo, Waltham, UK) were prepared for immunohistochemistry, to estimate the percentage of epithelial cells present in the purified suspension.

\subsection{One-dimensional SDS-PAGE and shotgun proteomics}

Individual mucosal wash samples, prepared as above, were pooled in a 1:1 ratio into four large samples characterised as either derived from naïve or immune tissue, and challenged or non-challenged in vitro with L3 larvae. Prior to creating the pooled samples, individual samples were run on a sodium dodecyl sulfate polyacrylamide gel electrophoresis (SDS-PAGE) gel, to assess the degree of variability between the samples. Protein content of the pooled samples was calculated with a standard bicinchoninic acid (BCA) protein assay kit (Pierce, Rockford USA). Samples were diluted with distilled water to ensure similar loadings of protein. 1-D gel electrophoresis (NuPage Novex BisTris gels, 4-12\% acrylamide; Invitrogen, Paisley, UK) was performed in the pooled samples and stained with Coomassie Blue (SimplyBlue Safestain, Invitrogen). Each of the gel lines was divided into 25 slices and each of the resulting 25 gel slices was then subjected to standard in-gel de-staining, reduction, alkylation and trypsinolysis procedures. Tryptic digests were transferred to sealed High Performance Liquid Chromatography (HPLC) sample vials and stored at $4{ }^{\circ} \mathrm{C}$ until required for analysis by an automated LC-ESI-MS/MS system. Liquid chromatography was performed using an Ultimate 3000 nano-HPLC system (Dionex, Sunnyvale, USA) comprising a WPS-3000 well-plate micro auto sampler, a FLM-3000 flow manager and column compartment, a UVD-3000 UV detector, an LPG-3600 dual-gradient micropump and an SRD-3600 solvent rack controlled by Chromeleon (Dionex) software. 
A micropump flow rate of $246 \mu \mathrm{L} / \mathrm{min}$ was used in combination with a cap-flow splitter cartridge, affording a $1 / 82$ flow split and a final flow rate of $3 \mu \mathrm{L} / \mathrm{min}$ through a $200 \mu \mathrm{m}$ ID monolithic reversed phase column (Dionex) maintained at a constant $50^{\circ} \mathrm{C}$. Samples of $4 \mu \mathrm{L}$ were applied to the column by direct injection. Peptides were eluted by the application of a 15 min linear gradient from $8 \%$ to $45 \%$ solvent B ( $80 \%$ acetonitrile, $0.1 \%$ formic acid) and directed through a $3 \mathrm{~nL}$ UV detector flow cell. LC was interfaced with a 3D high capacity ion trap mass spectrometer (Esquire HCTplus ${ }^{\mathrm{TM}}$, Bruker Daltonics, Coventry, UK) via ESI utilising a low-volume $(50 \mu \mathrm{L} / \min \max )$ stainless steel nebuliser (Agilent, South Queensferry, UK). MS/MS analysis was initiated on a contact closure signal triggered by Chromeleon software. This method provides a global analysis of complex protein mixtures [2,32].

Searches were performed using Mascot ${ }^{\mathrm{TM}}$ version 2.1 software (Matrix Science, London, UK) and the SwissProt and NCBInr databases. The interpretation of MS/MS data was performed in accordance with published guidelines [29]. The peptide and fragment mass tolerances applied were 1.5 and 0.5 daltons (Da) respectively. Individual MS/MS spectra for peptides with a Mascot Mowse score lower than 40 were inspected manually and only included in the statistics if a series of at least four continuous $\mathrm{y}$ or $\mathrm{b}$ ions were observed. Protein ID is based on the assignment of at least two peptides per protein, otherwise MS/MS spectra were verified manually.

\subsection{Two-dimensional SDS-PAGE gel electrophoresis and MALDI-Tof-MS}

Samples of epithelial cells were lysed in rehydration buffer (8 M urea, 2\% CHAPS, 0.4\% DTT, 0.2\% Biolytes 3-10 NL) prior to electrophoresis. Samples were initially vortexed for $1 \mathrm{~min}$, then agitated gently for $1 \mathrm{~h}$ at room temperature and centrifuged at $11000 \mathrm{~g} \times 15 \mathrm{~min}$. Cell extracts from individual (rather than pooled) samples were used for the two dimensional gel electrophoresis. Protein content of the individual samples was calculated with a standard 2-D Quant kit (Amersham, Buckinghamshire, UK). Samples were diluted with rehydration buffer to ensure similar protein loadings across samples. First dimension isoelectric focusing was carried out on immobilised $\mathrm{pH}$ gradient strips (18 cm, pH 3-10 NL, Amersham). Focusing was achieved at $8000 \mathrm{~V}$ for a minimum of $40000 \mathrm{Vhs}$.
After focusing, strips were equilibrated in $50 \mathrm{mM}$ Tris-HCl, $\mathrm{pH}$ 8.8, $6 \mathrm{M}$ urea, 30\% glycerol, 2\% SDS. Samples were initially reduced with the addition of DTT and then free cysteines were derivatised by the addition of iodoacetamide. Second dimension electrophoresis was performed on polyacrylamide $0.5 \mathrm{~mm}$ precast gels (ExcelGel XL SDS 12-14\%, Amersham). Total protein loadings for gels were approximately $150 \mu \mathrm{g}$. Gels were stained with SimplyBlue Safestain (Invitrogen). Spots of interest were excised from the gel and subjected to standard in-gel de-staining, reduction, alkylation and trypsinolysis procedures. Spots of interest included abundant spots or spots that appeared to change in intensity. The resulting digests were analysed using an Ultraflex ${ }^{\mathrm{TM}}$ II MALDI-ToF tandem mass spectrometer (Bruker Daltonics), scanning the 600-5000 Dalton region. The spectra generated were mass-calibrated using known standards and the peaks de-isotoped. Databases were searched with the masses obtained using the MASCOT search database and a $50 \mathrm{ppm}$ mass tolerance window. Levels of significance of the proteins that were a positive match were also calculated.

\subsection{Image analysis of 2-D gels}

Following SDS-PAGE, 2-D gels were imaged using a flat bed scanner (ImageScanner, Amersham). Image analysis and gel comparisons were performed using Progenesis PG200 software (Nonlinear dynamics, Newcastle, UK). This was done to allow comparison of spot intensity across the whole set of gels. Gels were automatically analysed using the spot detection feature of the software, with automated matching. Following matching of spots extensive checks were performed and mismatches were corrected manually. Spot volumes were corrected for background using the 'mode of non-spot method'. Spot volumes were normalised as a proportion of the total spot volume of the gel and results were multiplied by 1000 . Between gel comparisons for relevant spots were made by comparing relative spot volumes [10]. The latter were compared statistically between challenged naïve and immune tissue using $t$-test (Microsoft Excel).

\subsection{Western blots}

Western blots were performed for a selection of proteins, which may have an important role in immunity to parasites, in both mucosal wash samples and epithelial cell lysates. Preparations from 
epithelial cell lysates were run on $4-12 \%$ Bis-Tris minigels (Invitrogen) and were then transferred to nitrocellulose membrane (Invitrogen). The membrane was incubated for $1 \mathrm{~h}$ at room temperature in a solution containing $0.5 \%$ Tween $80,0.5 \mathrm{M}$ $\mathrm{NaCl}$ and PBS, which aimed to increase the stringency and reduce non-specific binding of the membrane. Membranes were then probed with affinity purified chicken anti-intelectin (1:500) [5]. Membranes were then washed five times with the high salt solution and probed with the secondary antibody (donkey-anti-chicken IgY-horseradisch peroxidase (HRP) conjugate, 1:10000; Jackson Laboratories; Maine, USA). After final washes, all blots were developed with chemiluminesence ECL (Amersham). Negative and positive controls were included.

Individual mucosal wash samples from in vitro challenged tissue were run on $12 \%$ SDS-PAGE minigels (Bio-rad, Hertfordshire, UK) and were then transferred to polyvinylidene fluoride (PVDF) membrane (Immobilon-P, Millipore, Hertfordshire, $\mathrm{UK})$. Membranes were incubated for $1 \mathrm{~h}$ at room temperature in solution containing 2\% Marvel in Tris buffered saline (TBS). Membranes were then probed with: (i) mouse anti-Immunoglobulin A (IgA, 1:1000, Serotec, Kidlington, UK); (ii) chicken anti-intelectin (ITLN, 1:500) [5]); (iii) rat monoclonal anti-Sheep Mast Cell Proteinase (SMCP, 1:10, dilution of tissue culture supernatant) [24]; and (iv) rabbit polyclonal antiCLCA ( $\mathrm{Cl}$ channel Ca-activated) antibody (1:500 of an affinity purified antibody stock $1 \mathrm{mg} / \mathrm{mL}$ ) that is directed against an amino-teminal epitope of mouse CLCA1/2, but also cross-reacts with mCLCA3 (alias gob-5) (Frank Thévenod, unpublished data). Following the washings, membranes were then probed with the secondary antibodies: (i) polyclonal rabbit anti-mouse HRP conjugate (1:1000, Dako, Cambridgeshire, UK) for the IgA; (ii) donkey-antichicken IgY-HRP conjugate (1:10 000; Sigma) for intelectin; (iii) rabbit anti-rat HRP conjugate (1:1000, Dako) for SMCP; and (iv) polyclonal goat anti-rabbit HRP (1:2000, Dako) for CLCA. Antibody dilutions were made with the blocking solution. After final washes, all blots were developed with chemiluminesence ECL (Sigma).

\subsection{Immunohistochemistry}

In order to check the purity of the epithelial cell population isolated from the gastric mucosa, gastric samples were fixed in zinc salt solutions at slaughter [8] for embedding and sectioning. Staining of ovine epithelial cells was achieved with mouse antibodies to pancytokeratin (1:2000, Sigma; clone PCK-26; broad spectrum antibody; reacts specifically with a variety of normal, reactive, and neoplastic epithelial tissues). Preliminary experiments showed that they were the most specific antibodies for ovine epithelial cells and thus were used for immunohistochemistry. Epithelial cell cytospins were also prepared to determine the purity of the epithelial cell suspension, and also stained for pancytokeratin. Cell counting was performed to determine the proportion of positively stained epithelial cells prior to preparation for the proteomic analysis. For sections and cytospins detection of mouse antipancytokeratin was performed using the Envision system (Dako).

\section{RESULTS}

\subsection{In vitro larval counts}

In previously naïve tissue, an average of $54 \%$ larvae was recovered from the tissue digests, compared to a $4 \%$ recovery from tissues deriving from previously exposed sheep $(P<0.05$; Fig. 1).

\subsection{Isolation of epithelial cells}

All types of mucosal epithelial cells stained positively with the anti-pancytokeratin antibody, but not inflammatory cells (Fig. 2A). The use of the enzymatic cocktail resulted in isolation of epithelial cells as shown in Figure 2B. Quantification of stained cells showed that in the cell suspension, routinely more than $85 \%$ of cells present were epithelial cells. Staining for viability showed that more than $97 \%$ of cells were viable at the end of the incubation.

\subsection{Identification of proteins of interest in epithelial cell lysates}

Approximately 50 spots of proteins of interest were analysed and 26 were positively identified. The location of the identified spots is indicated in Figure 3 by the gene name. The reference map (Fig. 3) shows a typical epithelial cell lysate from immune gastric

(page number not for citation purpose) Page 5 of 16 


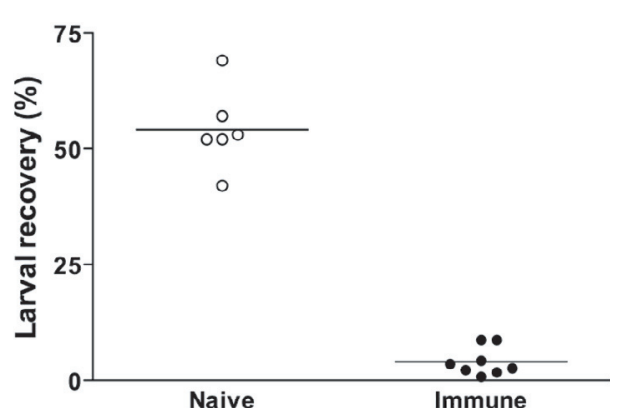

Figure 1. Percentage of infective larvae recovered from tissue digest of sheep either naïve (open circles) or immune (closed circles) to parasites, following the in vitro challenge with 2500 Teladorsagia circumcincta L3. Tissue from each sheep was challenged in triplicate; each point represents the mean of three replicates. The horizontal line represents the mean for each group.

tissue. Mascot search data for all these proteins are presented in Table I. The level of significance of each hit is also shown in Table I. A small number of spots did not provide a significant ovine/bovine (or parasite) hit and thus were excluded from the reference map and Table I.

The study focused on proteins that were differentially expressed, in the epithelial cell lysates from naïve and immune gastric mucosa. Spots of interest included abundant spots or spots that appeared to change in intensity between immune and naïve mucosa. Figure 4 shows the total spot volume of two proteins that were statistically shown to be differentially expressed between naïve and immune tissue following the in vitro challenge. Lysozyme 1 (LYZ1) was up regulated in immune samples (Fig. 4); similarly, intelectin 2 (ITLN2) was up-regulated in immune tissue $(P<0.05)$. ITLN2 spots in particular were positively identified from 6 out of 8 immune animals, whereas they were identified in one of the naïve samples. Other proteins, such as endoplasmin (HSP90B1), were more highly expressed in naïve tissue, although the difference observed between naïve and immune tissue was not significant. No other proteins, whether identified or not, differed

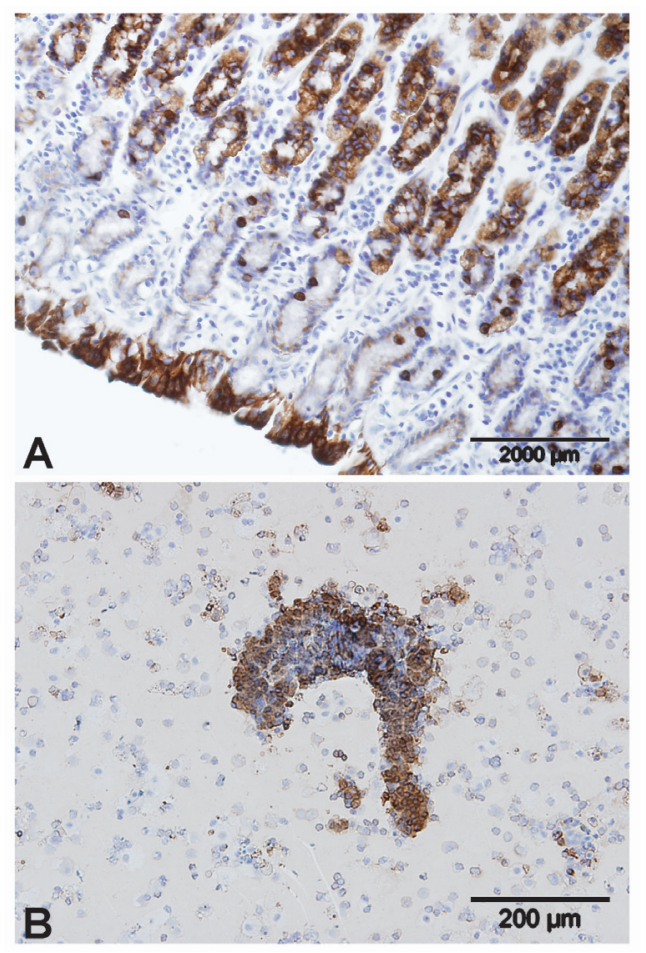

Figure 2. (A) Gastric epithelium fixed with Zinc salts and stained with pancytokeratin antibody. The staining was specific for surface mucus cells, mucus neck cells and gastric chief cells, whereas no inflammatory cells are stained. (B) Epithelial cell cytospin following the enzymatic dispersion of epithelial cells from the gastric mucosa. Cytospin was fixed in cold methanol and stained with pancytokeratin antibody. Note the intact gastric pit.

significantly between immune and naïve samples.

\subsection{Analysis of mucosal wash by \\ LC-ESI-MS/MS}

Mucosal washings deriving from previously naïve or immune gastric tissue, with or without in vitro larval challenge, were analysed by LC-ESI-MS/MS in combination with database searching against NCBI and SwissProt databases. Numerous proteins were identified from each sample. A total of 74 proteins with significant identity were 


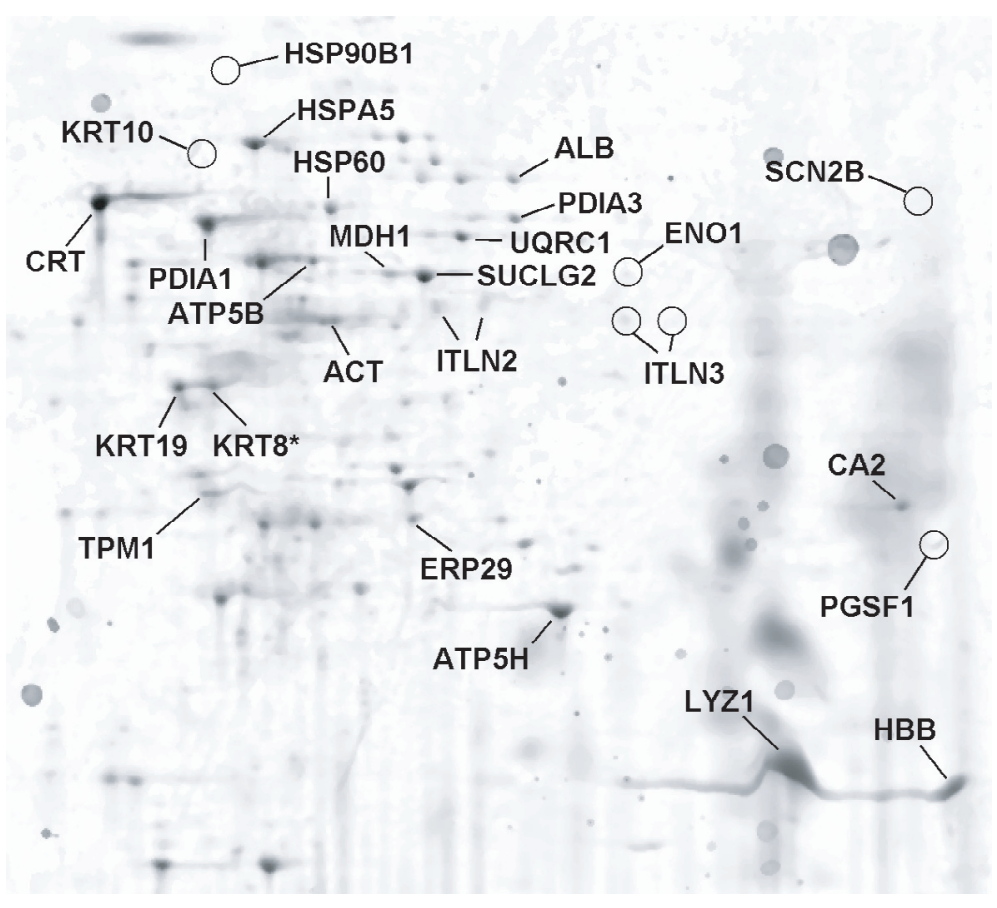

Figure 3. Two-dimensional electrophoretic reference map of epithelial cells derived from immune gastric mucosa following in vitro challenge with $2500 \mathrm{~T}$. circumcincta L3. Proteins were identified by tryptic peptide mapping from Coomassie-blue stained gels. The locations of the spots identified in other gels, but which were not present in this specific gel, are shown with open circle.

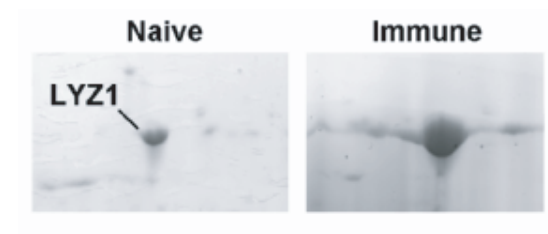

Lysozyme-1

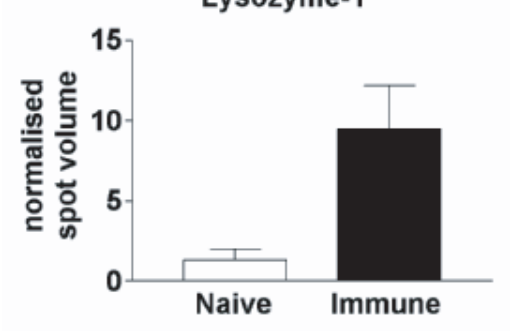

Naive
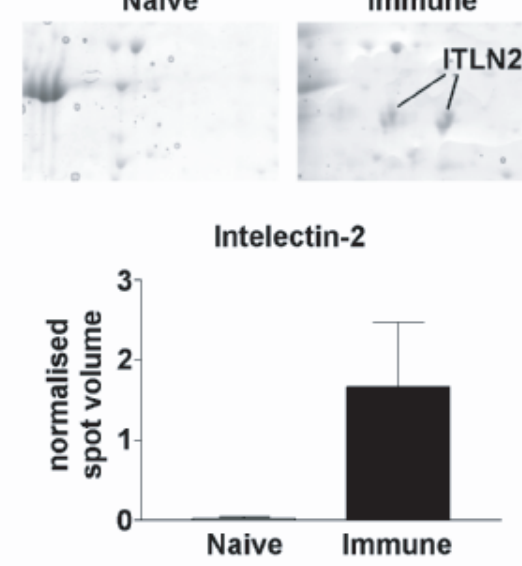

Figure 4. Total spot volume of lysozyme (LYZ1) and intelectin 2 (ITLN2) spots as detected by 2-DE of epithelial cell lysates from naïve or immune gastric tissue following in vitro challenge with 2500 T. circumcincta L3. Vertical bars indicate standard errors. Examples from typical 2-DE gels are shown. 
Table I. List of proteins recovered from 2-DE gels from epithelial cell lysates, following the in vitro challenge of previously naïve or immune tissue with 2500 T. circumcincta L3. Peptide sequences were searched against NCBI and Swiss-Prot databases. The Mascot score, number of peptides matched and sequence coverage are shown, as well as theoretical expected MW and pI.

\begin{tabular}{|c|c|c|c|c|c|c|c|c|}
\hline $\begin{array}{l}\text { Gene name } \\
\text { (Swiss-Prot) }\end{array}$ & $\begin{array}{l}\text { Identity } \\
\text { MASCOT }\end{array}$ & $\begin{array}{l}\text { Accession } \\
\text { No. }\end{array}$ & $\begin{array}{c}\text { Mascot } \\
\text { score }\end{array}$ & $\begin{array}{c}\text { Level of } \\
\text { significance }\end{array}$ & $\begin{array}{l}\text { Peptides } \\
\text { matched }\end{array}$ & $\begin{array}{c}\text { Coverage } \\
(\%)\end{array}$ & $\begin{array}{c}\exp \mathrm{MW} \\
\mathrm{kDa}\end{array}$ & $\operatorname{exp~pI}$ \\
\hline ACT & Actin (Bos taurus) & gi|54036676 & 99 & $\mathrm{y}$ & 17 & $50 \%$ & 41.7 & 5.31 \\
\hline ALB & Serum albumin (Ovis aries) & gi|57164373 & 122 & $\mathrm{y}$ & 14 & $31 \%$ & 71 & 5.8 \\
\hline ATP5B & ATP synthase beta chain (Bos taurus) & gi|28461221 & 200 & $\mathrm{y}$ & 37 & $78 \%$ & 56.2 & 5.15 \\
\hline ATP5H & ATP synthase $\mathrm{d}$ chain (Bos taurus) & gi|27807305 & 83 & $\mathrm{y}$ & 9 & $60 \%$ & 18.7 & 6 \\
\hline CA2 & Carbonic anhydrase 2 (Ovis aries) & gi||118582300 & 68 & $\mathrm{y}$ & 8 & $44 \%$ & 29.2 & 6.4 \\
\hline CRT & Calreticulin (Bos taurus) & gi|27806723 & 193 & $\mathrm{y}$ & 21 & $52 \%$ & 48.1 & 4.31 \\
\hline ENO1 & Enolase 1 (Bos taurus) & gi|87196501 & 101 & $\mathrm{y}$ & 13 & $37 \%$ & 47.6 & 6.4 \\
\hline ERP29 & Endoplasmic reticulum protein 29 (Bos taurus) & gi||115495555 & 116 & $\mathrm{y}$ & 12 & $43 \%$ & 28.8 & 5.6 \\
\hline HBB & Hemoglobin beta subunit (Ovis aries) & gi|122546 & 128 & $\mathrm{y}$ & 10 & $77 \%$ & 16.1 & 6.75 \\
\hline HSP60 & $60 \mathrm{kDa}$ heat shock protein (Bos taurus) & gi|76644268 & 144 & $\mathrm{y}$ & 17 & $34 \%$ & 61.1 & 5.7 \\
\hline HSP90B1 & Endoplasmin (Bos taurus) & gi|33301108 & 108 & $\mathrm{y}$ & 19 & $27 \%$ & 92.3 & 4.76 \\
\hline HSPA5 & $78 \mathrm{kDa}$ glucose regulated protein (Bos taurus) & gi|122144501 & 153 & $\mathrm{y}$ & 30 & $46 \%$ & 72.2 & 5.07 \\
\hline ITLN2 & Intelectin 2 (Ovis aries) & gi|145308887 & 124 & $\mathrm{y}$ & 12 & $41 \%$ & 36.4 & 5.8 \\
\hline ITLN3 & Intelectin-3 (Ovis aries) & gi $\mid 157886697$ & 130 & $\mathrm{y}$ & 11 & $39 \%$ & 36.6 & 8.8 \\
\hline KRT10 & Keratin 10 (Bos taurus) & gi|27805977 & 82 & $\mathrm{y}$ & 14 & $21 \%$ & 55 & 5 \\
\hline KRT19 & Keratin type 1, cytoskeletal 19 (Bos taurus) & gi|62751472 & 184 & $\mathrm{y}$ & 20 & $51 \%$ & 43.8 & 4.9 \\
\hline KRT8* & Keratin type ii cytoskeletal 8 (Bos taurus)- fragment & gi|75812916 & 133 & $\mathrm{y}$ & 15 & $30 \%$ & 53.6 & 5.7 \\
\hline LYZ1 & Lysozyme 1 (Ovis aries) & gi $\mid 5802272$ & 141 & $\mathrm{y}$ & 8 & $66 \%$ & 14.3 & 6.08 \\
\hline MDH1 & Cytosolic malate dehydrogenase (Bos taurus) & gi|77736203 & 64 & $\mathrm{n}(0.072)$ & 9 & $31 \%$ & 36.7 & 6.2 \\
\hline PDIA1 & Protein disulfide isomerase A1 (Bos taurus) & gi|148878430 & 274 & $\mathrm{y}$ & 25 & $53 \%$ & 57.6 & 4.8 \\
\hline PDIA3 & Protein disulfide-isomerase A3 (Bos taurus) & gi|729433 & 91 & $\mathrm{y}$ & 17 & $36 \%$ & 57.3 & 6.2 \\
\hline PGFSI & Prostaglandin-F synthase 1 (Bos taurus) & gi|119905464 & 63 & $\mathrm{n}(0.077)$ & 8 & $17 \%$ & 29.7 & 6.8 \\
\hline $\mathrm{SCN} 2 \mathrm{~B}$ & Sodium channel beta- 2 subunit (Canis familiaris) & gi|73955080 & 52 & $\mathrm{n}(0.081)$ & 9 & $16 \%$ & 56.5 & 7.9 \\
\hline SUCLG2 & Succinyl-CoA ligase (GDP-forming) beta-chain (Bos taurus) & gi|146231894 & 120 & $\mathrm{y}$ & 12 & $34 \%$ & 47 & 7.5 \\
\hline TPM1 & Tropomyosin 3 isoform 2 isoform 18 (Canis familiaris) & gi|73961101 & 104 & $\mathrm{y}$ & 15 & $40 \%$ & 26.6 & 4.8 \\
\hline UQCRC1 & Ubiquinol-cytochrome-c reductase complex core protein 1 (Bos taurus) & gi|4139392 & 202 & $\mathrm{y}$ & 18 & $56 \%$ & 50 & 5.5 \\
\hline
\end{tabular}

n: Non significant hit; y: significant hit. 


\section{Naive $(n=6)$}

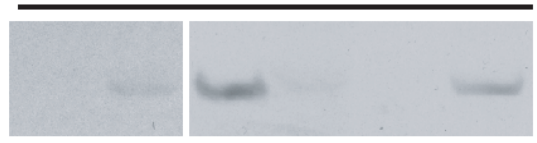

Immune $(\mathrm{n}=8)$

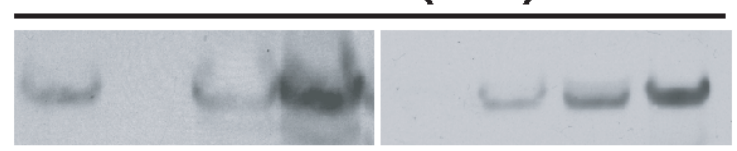

Figure 5. Western blots of intelectin in individual samples of epithelial cell lysates, following the in vitro challenge with $2500 T$. circumcincta L3. ITLN was detected in 3 out of 6 samples that were naïve prior to the in vitro challenge, whereas it was highly expressed in 6 out of 8 samples that were immune prior to the in vitro challenge.

recovered from the mucosal washes. The minimum score that was considered significant was 50 with a minimum of two matched peptides. Within each individual sample, a cumulative score was calculated for each identified protein, to account for cases where a protein was present in more than one gel slice. Although this score gives a suggestion as to the relative amount of a particular protein in a particular sample, it should be stressed that this is not quantitative, and should not be over interpreted. Although the results give reliable evidence for the existence of specific proteins in mucosal washes, any apparent differences between samples must be treated with caution. The proteins identified in each sample are shown in Table II. In cases where there were multiple hits for particular proteins, hits deriving from ovine or bovine databases are presented. Proteins with the highest Mascot score, and likely to be among the most highly abundant proteins in mucosal washes included serum albumin, complement component 3, heat shock cognate $71 \mathrm{kDa}$ protein, creatine kinase, gelsolin and lysozymes. The identified proteins were categorised as those involved in the cytoskeleton, plasma proteins, or indicators of innate and adaptive immune responses. Proteins that were identified in the mucosal wash of immune, but not naïve tissue, included SMCP, IgA, and galectins 14 and 15. ITLN and CLCA were only present in the wash deriving from immune tissue following the parasite challenge. Conversely, fatty acid binding protein 5 was observed only in naïve washes. In addition to those proteins, nuclear proteins, such as histones, and a variety of enzymes were present in all samples, including carbonic anhydrase, alpha enolase, glutathione-s transferase, creatine kinase and proteinase inhibitors.

\subsection{Western blots of proteins of interest in epithelial cells lysates and mucosal washes}

Representative Western blots were performed to validate the proteomic findings and in general they achieved to do so. In the individual epithelial cell lysates samples, ITLN was highly visible with strong reactive bands in 6 out of 8 immune samples; in only 3 out of 6 naïve samples there was a weak reactivity, whereas no reactive bands were observed in the remaining naïve samples (Fig. 5). Western blots on individual mucosal wash samples were also performed for IgA, ITLN, SMCP and CLCA (Fig. 6); as seen in Figure 6, strong bands for all these proteins were observed in the majority of immune challenged samples, but not in naïve challenged samples. This was in accordance with the proteomic analysis of the mucosal washes.

\section{DISCUSSION}

The present study utilized an in vitro organ challenge system and employed a global approach to identify effector molecules that may be responsible for the exclusion of infective $T$. circumcincta from the gastric mucosa, in the mucus and epithelial cell extracts. This in vitro system was used to examine the critical first phase of the establishment process, when larvae come in close association with the tissue [13]. The pattern observed i.e. fewer larvae being closely 


\begin{tabular}{|c|c|c|c|c|c|c|c|c|}
\hline \multirow[b]{2}{*}{ Accession No. NCBI } & \multirow[b]{2}{*}{ Species } & \multirow[b]{2}{*}{ Protein name } & \multirow[b]{2}{*}{ MW (Da) } & \multirow[b]{2}{*}{ Identity hit } & \multicolumn{2}{|c|}{ Naïve } & \multicolumn{2}{|c|}{ Immune } \\
\hline & & & & & - & + & - & + \\
\hline Heat shock proteins an & perones & & & $\begin{array}{l}\text { MASCOT score } \\
\text { (No. of peptides } \\
\text { matched) }\end{array}$ & Cun & ative $\mathrm{N}$ & SCOT & core \\
\hline gi|66356310 & Ovis aries & 78 kDa glucose-regulated protein (GRP 78) & 45241 & $113(3)$ & & & & 113 \\
\hline gi|148887198 & Bos taurus & Heat shock cognate $71 \mathrm{kDa}$ protein & 71424 & $325(16)$ & 249 & 447 & 301 & 543 \\
\hline \multicolumn{9}{|l|}{ Cytoskeleton } \\
\hline gi|114051526 & Bos taurus & Coactosin & 16114 & $104(3)$ & 104 & 85 & 74 & 95 \\
\hline gi|2665740 & Ovis aries & Beta actin & 28096 & $109(9)$ & 275 & 280 & 111 & 159 \\
\hline gi|61553131 & Bos taurus & Alpha 2 actin & 45705 & $81(6)$ & & 81 & & \\
\hline gi|78369242 & Bos taurus & Actinin alpha-1 & 103486 & $101(5)$ & & 101 & & 52 \\
\hline gi|119912356 & Bos taurus & Keratin 13 & 50660 & $85(3)$ & & \multicolumn{3}{|c|}{85} \\
\hline gi| 134085706 & Bos taurus & Keratin 6 & 61182 & $199(10)$ & & \multicolumn{3}{|c|}{199} \\
\hline gi114051856 & Bos taurus & Keratin 7 & 51603 & $148(6)$ & & 52 & 231 & \multirow[t]{2}{*}{137} \\
\hline gi|75812916 & Bos taurus & Keratin 8 & 53552 & $143(5)$ & & 218 & 189 & \\
\hline gi|27806351 & Bos taurus & Villin 2 & 68832 & $291(15)$ & 87 & 51 & 117 & 291 \\
\hline gi|75775321 & Bos taurus & Vitamin D-binding protein precursor & 54904 & $53(4)$ & 69 & & 53 & 100 \\
\hline gi| 114050715 & Bos taurus & Moesin & 68047 & $70(6)$ & 70 & & 76 & \\
\hline gi|77736201 & Bos taurus & Gelsolin b & 80966 & $233(10)$ & 189 & 138 & 230 & 277 \\
\hline gi|61888874 & Bos taurus & Transgelin 2 & 22583 & $176(9)$ & 331 & 358 & 138 & 246 \\
\hline gi|28603774 & Bos taurus & Rho GDP dissociation inhibitor (GDI) alpha & 23464 & $67(5)$ & 57 & & 67 & \\
\hline gi|62751593 & Bos taurus & Profilin 1 & 15219 & $272(16)$ & 346 & 169 & 205 & 352 \\
\hline gi| 115496125 & Bos taurus & Radixin & 68639 & $81(5)$ & & & & 81 \\
\hline gi|543113 & Bos taurus & Smooth muscle protein SM22 & 19326 & $139(8)$ & 139 & & & \\
\hline \multicolumn{9}{|l|}{ Nucleus } \\
\hline gi| 118151208 & Bos taurus & Histone H2B & 13867 & $108(10)$ & 52 & 74 & 185 & 313 \\
\hline gi|61845671 & Bos taurus & Histone 4 & 11388 & $114(5)$ & 179 & 107 & 108 & 56 \\
\hline
\end{tabular}




\begin{tabular}{|c|c|c|c|c|c|c|c|c|}
\hline $\begin{array}{l}\text { Plasma proteins } \\
\text { gi|57164373 }\end{array}$ & Ovis aries & Serum Albumin & 71139 & $2106(99)$ & 5349 & 3566 & 4522 & 5477 \\
\hline gi|83764016 & Bos taurus & Complement component 3 & 188715 & $122(5)$ & 120 & 50 & 396 & 432 \\
\hline gi|157954061 & Bos taurus & A-2 macroglobulin precursor & 168953 & $211(13)$ & 85 & & 301 & 245 \\
\hline gi|57164383 & Ovis aries & Antithrombin III & 52979 & $116(5)$ & 116 & & & 56 \\
\hline gi|75831056 & Bos taurus & Apolipoprotein A1 & 30258 & $82(2)$ & 82 & 56 & & \\
\hline gi|164448674 & Ovis aries & Beta globin & 16050 & $140(10)$ & 39 & 228 & 53 & 63 \\
\hline gi|949666763 & Bos taurus & Haptoglobin & 45629 & $59(3)$ & & 59 & & \\
\hline gi|29135265 & Bos taurus & Transferrin & 79856 & $183(11)$ & 283 & 304 & 338 & 223 \\
\hline gi|57526651 & Ovis aries & Transthyretin & 15875 & $57(2)$ & 57 & & & \\
\hline gi|1787 & Ovis aries & Alpha globin chain & 15250 & $66(3)$ & & 106 & 114 & 63 \\
\hline gi|57526674 & Ovis aries & Fetuin & 39511 & $50(4)$ & & 50 & & \\
\hline gi|31340900 & Bos taurus & Serine proteinase inhibitor (SERPINA 3) & 46289 & $95(2)$ & 145 & 78 & 66 & 169 \\
\hline gi|165839 & Ovis aries & Beta lactoglobulin & 20334 & $304(10)$ & & 541 & & \\
\hline Cellular proteins & & & & & & & & \\
\hline gi|76669648 & Bos taurus & Annexin 10 & 37521 & $253(10)$ & 63 & 140 & 135 & 253 \\
\hline gi|27807289 & Bos taurus & Annexin A2 & 38873 & $139(8)$ & & 48 & 71 & 139 \\
\hline gi|120474983 & Bos taurus & Annexin A5 & 36109 & $189(9)$ & 104 & 78 & 99 & 283 \\
\hline gi|74 & Bos taurus & Annexin I & 39158 & $195(10)$ & 56 & 175 & 264 & 216 \\
\hline gi|74354599 & Bos taurus & Phosphatidylethanolamine binding protein & 21106 & $63(2)$ & 145 & 50 & 59 & 75 \\
\hline gi|62751970 & Bos taurus & Chloride intracellular channel 1 & 27317 & $67(4)$ & & 67 & & \\
\hline gi|27805805 & Bos taurus & Fatty acid binding protein 5 & 15350 & $80(3)$ & 80 & 75 & & \\
\hline gi|32189340 & Bos taurus & Adenine nucleotide translocator & 33174 & $55(2)$ & 55 & & & \\
\hline Enzymes & & & & & & & & \\
\hline gi| 57526379 & Ovis aries & Aldehyde dehydrogenase & 55417 & $159(9)$ & 159 & & & \\
\hline gi|156120479 & Bos taurus & Aldolase A & 39925 & $68(9)$ & & & & 68 \\
\hline gi|4927286 & Bos taurus & Alpha enolase & 47589 & $198(9)$ & 188 & 219 & 179 & 252 \\
\hline gi|119910440 & Bos taurus & ATPase, $\mathrm{H}+/ \mathrm{K}+$ exchanging, alpha polypeptide variant & 115873 & $57(2)$ & 57 & & & \\
\hline gi|118582300 & Ovis aries & Carbonic anhydrase 2 & 29193 & $69(8)$ & & 119 & 68 & 56 \\
\hline gi|13096153 & Bos taurus & Creatine Kinase & 42836 & $209(11)$ & 49 & 322 & 374 & 285 \\
\hline gi|57164307 & Ovis aries & Cytosolic NADP-isocitrate dehydrogenase & 47153 & $101(4)$ & 78 & 101 & & \\
\hline
\end{tabular}


Table II. Continued.

\begin{tabular}{|c|c|c|c|c|c|c|c|c|}
\hline \multirow[b]{2}{*}{ Accession No. NCBI } & \multirow[b]{2}{*}{ Species } & \multirow[b]{2}{*}{ Protein name } & \multirow[b]{2}{*}{ MW (Da) } & \multirow[b]{2}{*}{ Identity hit } & \multicolumn{2}{|c|}{ Naïve } & \multicolumn{2}{|c|}{ Immune } \\
\hline & & & & & - & + & - & + \\
\hline gi|83035079 & Bos taurus & Glutaredoxin or Thioltransferase 1 & 12003 & $53(2)$ & 53 & & & 61 \\
\hline gi|28461273 & Bos taurus & Glutathione S-transferase Pi & 25789 & $130(6)$ & 141 & 112 & 130 & 126 \\
\hline gi|10505253 & Bos taurus & Hypoxanthine phosphoribosyltransferase & 21151 & $71(2)$ & 79 & 71 & & 53 \\
\hline gi|27807469 & Bos taurus & Peroxiredoxin 2 & 22217 & $64(3)$ & 55 & 48 & 76 & 144 \\
\hline gi| 57526769 & Ovis aries & Preprochymosin & 42447 & $177(11)$ & & 356 & & \\
\hline gi|119903961 & Bos taurus & Protein disulfide-isomerase & 64930 & $80(4)$ & & & & 80 \\
\hline gi|47606778 & Bos taurus & Ribonuclease UK114 & 14347 & $79(6)$ & & & & 79 \\
\hline gi|57164261 & Ovis aries & Thioredoxin & 12090 & $57(2)$ & 54 & & 57 & \\
\hline gi|61888856 & Bos taurus & Triose phosphate isomerase & 26901 & $63(2)$ & & 63 & & \\
\hline gi|530049 & Ovis aries & Tyrosine 3 monooxygenase tryprophane 5 & 26450 & $98(5)$ & 56 & 168 & 81 & 165 \\
\hline \multicolumn{9}{|c|}{ Adaptive immune responses } \\
\hline gi|109029 & Ovis aries & Ig heavy chain $\mathrm{C}$ region & 34327 & $292(25)$ & 212 & 301 & 492 & 417 \\
\hline gi|109030 & Ovis aries & Ig lambda chain $\mathrm{C}$ region - sheep & 11476 & $427(15)$ & 548 & 129 & 81 & 451 \\
\hline gi|52366986 & Ovis aries & Ig lamda light chain region segment 1 & 11493 & $621(22)$ & 540 & 394 & 838 & 995 \\
\hline gi|165945 & Ovis aries & IgM chain & 54197 & $147(6)$ & 66 & & 147 & 56 \\
\hline gi|2582411 & Ovis aries & IgA heavy chain & 51292 & $387(12)$ & & & 75 & 387 \\
\hline gi|7547266 & Bos taurus & IgG1 heavy chain constant region & 36510 & $67(6)$ & & & & 67 \\
\hline \multicolumn{9}{|c|}{ Innate immune responses } \\
\hline gi|119919506 & Bos taurus & Mucin 5 & 407449 & $83(8)$ & 83 & & & \\
\hline gi|57163983 & Ovis aries & Galectin 14 & 18354 & $61(3)$ & & & 61 & \\
\hline gi|57163975 & Ovis aries & Galectin 15 & 15621 & $167(8)$ & & & 180 & 256 \\
\hline gi| 145308887 & Ovis aries & Intelectin 2 & 36386 & $56(3)$ & & & & 56 \\
\hline gi| 165970 & Ovis aries & Lysozyme $2 \mathrm{a}$ & 14833 & $255(24)$ & & 447 & 147 & 391 \\
\hline gi|27923983 & Ovis aries & Lysozyme C-1 & 16698 & $416(30)$ & 471 & 271 & 53 & 528 \\
\hline gi|57164171 & Ovis aries & Mast cell proteinase 1 & 27202 & $74(3)$ & & & 74 & 93 \\
\hline gi|76613482 & Bos taurus & Calcium activated chloride channel 1 & 101004 & $76(3)$ & & & & 76 \\
\hline
\end{tabular}




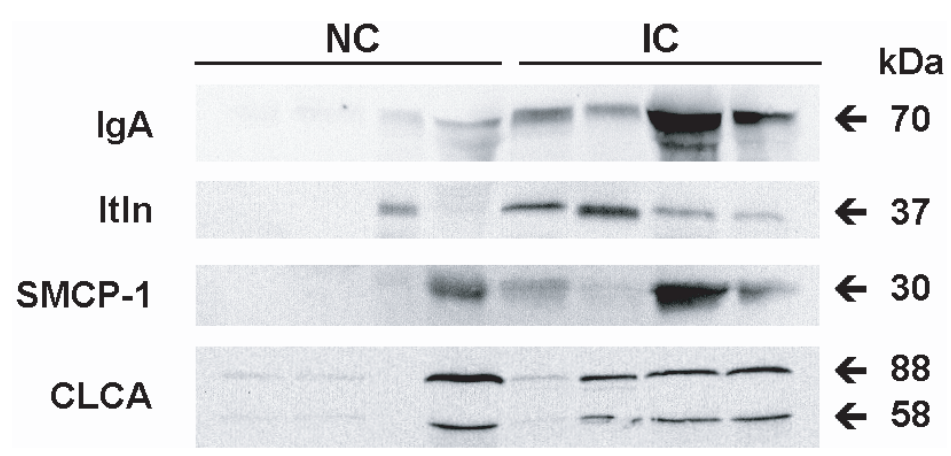

Figure 6. Western blots of individual mucosal wash samples either naïve $(\mathrm{N})$ or immune (I) prior to the in vitro challenge with $2500 \mathrm{~L} 3$ of $T$. circumcincta probed with antibodies to (a) IgA, (b) ITLN, (c) SMCP1, (d) CLCA. See material and methods for details.

associated with previously immune tissue than previously naïve tissue, is in agreement with previous studies, where both in vitro tissue association [13] and in vivo larval establishment in naïve tissue were shown to be between $30-60 \%$ [27]. The present study showed that the tissue explants can maintain immunological function in vitro, at least for the time tested in this study. From the changes observed in the protein content of epithelium and mucus following larval challenge it is apparent that the in vitro model provided a technique which can be usefully deployed in investigations into recently established or immediate tissue responses to larval challenge.

The use of the described enzymatic methodology for the isolation of epithelial cells from the gastric mucosa was based on the previously described method for the isolation of gastric crypts of bovine mucosa described by Dziva et al. [4]. Cytospins confirmed that there was minimal contamination from non-epithelial lamina propria derived cells, compared to other methods used to isolate epithelial cells, such as mucosal scrapings and the use of EDTA (preliminary data, not included here), and only minimal contamination with albumin was observed in 2-D gels. The epithelial cells retained much of their viability during their isolation, although some dead cells (3\%) were also observed. The analysis of the two-dimensional gel electrophoresis of epithelial cell lysates revealed that a number of proteins identified were differentially expressed in naïve and immune cells. For example, intelectin and lysozymes were more abundant in epithelial cell lysates from immune samples. ITLN is a calcium dependent lectin, which can recognise galactofuranose containing components of bacterial cell walls. It has been shown to be expressed by the Paneth cells in the small intestine of mouse [15] and the mucus neck cells in the abomasum of sheep [5]. Of particular interest is the finding that high ITLN expression was related to nematode expulsion in T. spiralis rodent models [25]. Furthermore, it has recently been shown to be highly expressed in the gastric mucosa of sheep infected with $T$. circumcincta, during the phase of parasite expulsion [6]. The authors suggest that this protein plays an important role in the exclusion of infective larvae from the gastric mucosa, and the present finding of increased levels of intelectin in epithelial cells from immune tissue, compared to those from naïve tissue, is supportive of this hypothesis. Although ITLN was detected at a low level in cell lysates from naïve epithelium, the increased level of expression in immune epithelium and its presence in mucus following larval challenge provides further supportive evidence of a possible role for ITLN in the host response to nematodes. Increased levels of both intracellular and mucus-related ITLN supports increased expression and release of this protein. 
Although previous work has investigated histological and immunohistological changes in mucus from excised immune gastrointestinal tissue $[19,20]$, the in vitro challenge model enabled a comparative study of the mucus contents within $2 \mathrm{~h}$ following larval challenge. This immediacy allowed a comparative analysis of proteins actively secreted into the mucus, in response to the larval challenge, and should reflect the functional activity of these tissues. The methodology used to attain the mucus for the proteomic analysis from the gastric mucosa, was the least invasive one as evaluated with histological sections of the gastric mucosa following the procedure. Alternative procedures tested included the use of swabs and gentle mucosal scraping to remove mucus (preliminary data not showed here). Although a small degree of contamination with epithelial cells can not be excluded, we are confident that such contamination was minimal and most of the proteins identified in the mucosal wash were derived from the mucus layer itself. As cytosolic and nuclear proteins were identified during the shotgun analysis, it is possible that the presence of some proteins identified in the mucosal wash, such as the nuclear histones $\mathrm{H} 4$ and $\mathrm{H} 2 \mathrm{~B}$, may have been due to cell lysis rather than secretion. The products from lysed epithelial cells constitute a well documented component of mucus [22].

A number of proteins were identified in the mucosal wash from previously immune tissue, which were not present in the mucosal wash of the naïve tissue and thus may constitute proteins which are associated with the development of the adaptive immune response to nematodes. Examples of these were $\operatorname{IgA}$, Galectin 14 and 15 and SMCP1, all of which have previously been shown to be up-regulated in gastric tissues in association with immunity to nematodes. IgA mediated suppression of nematode growth and fecundity appears to be one of the key mechanisms of resistance to T. circumcincta in sheep [28]. Furthermore, levels of local IgA in the lymph of sheep parasitised with $T$. circumcincta were higher in immune than in naïve sheep [9]. Galectins are carbohydrate-binding proteins that have been increasingly implicated in adaptive immune responses to nematodes. Galectin 14 in particular, is expressed by eosinophils which characteristically accumulate at the site of infection [18]. Similarly, galectin 15 (OVGAL11) expression was shown to be greatly upregulated in helminth larval infected gastrointestinal tissue subject to inflammation and eosinophil infiltration [3]. Immunohistological analysis has showed that the protein is localized in the cytoplasm and nucleus of upper epithelial cells of the gastrointestinal tract and it has also been detected in mucus samples collected from infected abomasum but not from uninfected tissue [3]. Gastrointestinal infection is characterised by the presence of increased numbers of mucosal mast cells, and these are pivotal in the immediate hypersensitivity reaction associated with immune rejection of nematode parasites in rodents [12, $21]$. During the process of immune expulsion, mast cells actively secrete a range of effector molecules, including histamine, monoamines, leukotrienes and proteases. The latter includes the secretion of SMCP1 [11] following experimental larval challenge in immune sheep. In mice, lack of the mast cell protease MMCP-1 resulted in delayed expulsion of the nematode Trichinella spiralis [14]. Thus, although the release and identification of these compounds was of no surprise, it does indicate that the in vitro challenged tissue responded in a manner consistent with previous in vivo studies, and is consistent with retention of functional activity within the tissue following challenge.

Of particular interest in the present study was the demonstration of increased levels of intelectin and CLCA in challenged mucus. While intelectin has been previously implicated in immunity to nematodes [6], the demonstration of a secreted CLCA protein in response to parasite challenge is novel. CLCA proteins are putative $\mathrm{Ca}^{2+}$-activated $\mathrm{Cl}^{-}$channels or channel regulators but have also been shown to affect epithelial secretion, cell-cell adhesion, apoptosis, cell cycle control, and mucus production (for review, see $[16,30]$ ). hCLCA1 and mCLCA3 (alias gob5) are distributed in mucin producing goblet cells [16]. Recent studies have shown that all subunits of hCLCA1 and mCLCA3 are 
secreted soluble proteins rather than being trans-membrane proteins [7, 23]. Expression of hCLCA1 or mCLCA3 was found to be up-regulated following exposure to respiratory tract irritants that are responsible for a Th2 local inflammation [26, 34]. It has been shown that at transcript and protein level, expression of hCLCA1 was up-regulated by IL-13 in normal human bronchial epithelial cells in vitro [33]. Whether the secretion of the ovine CLCA protein has a direct or indirect function in worm expulsion remains unknown, although hCLCA1 has been associated with an increase in mucus production following a Th2 response of the respiratory tract [34]. Furthermore, increased expression of IL-9 resulted in increased expression of hCLCA1 mRNA by epithelial cells in patients suffering from asthma [31] suggesting that hCLCA1 may be responsible at least in part for the overproduction of mucus by the asthmatic patients. Increased volume or viscosity of mucus may result in entrapment of infective larvae and thus reduced establishment in tissues that have been previously challenged with the parasite. A similar mechanism of action of mucus has been hypothesised during the phase of expulsion of nematodes [20].

In conclusion, the exclusion of infective larvae from the gastric mucosa is associated with altered levels of a variety of proteins, most of which are directly related to the acquired Th2 pro-inflammatory response, as well as to innate immunity. The usefulness of this in vitro model has been confirmed, and the global proteomic approach has identified proteins having a potential role in the parasite exclusion from abomasal mucosa. Further attempts should be concentrated in quantifying their expression at transcript and protein level and identifying the role of these proteins in the exclusion of infective larvae.

Acknowledgements. The project was funded by the Department for Environment, Food and Rural Affairs/Scottish Higher Education Funding Council (DEFRA/SHEFC) Veterinary Training and Research Initiative (VTRI; VT0102). The Scottish Agricultural College and the Moredun Research Institute receive financial support by Scottish Government Rural Directorate. Research in the laboratory of F. Thévenod was funded by German Cystic Fibrosis foundation (Grant No. F04/04).

\section{REFERENCES}

[1] Balic A., Bowles V.M., Meeusen E.N., The immunobiology of gastrointestinal nematode infections in ruminants, Adv. Parasitol. (2000) 45:181-241.

[2] Batycka M., Inglis N.F., Cook K., Adam A., FraserPitt D., Smith D.G., et al., Ultra-fast tandem mass spectrometry scanning combined with monolithic column liquid chromatography increases throughput in proteomic analysis, Rapid Commun. Mass Spectrom. (2006) 20:2074-2080.

[3] Dunphy J.L., Balic A., Barcham G.J., Horvath A.J., Nash A.D., Meeusen E.N., Isolation and characterization of a novel inducible mammalian galectin, J. Biol. Chem. (2000) 275:32106-32113.

[4] Dziva F., Mahajan A., Cameron P., Currie C., McKendrick I.J., Wallis T.S., et al., EspP, a Type V-secreted serine protease of enterohaemorrhagic Escherichia coli O157:H7, influences intestinal colonization of calves and adherence to bovine primary intestinal epithelial cells, FEMS Microbiol. Lett. (2007) 271:258-264.

[5] French A.T., Bethune J.A., Knight P.A., McNeilly T.N., Wattegedera S., Rhind S., et al., The expression of intelectin in sheep goblet cells and upregulation by interleukin-4, Vet. Immunol. Immunopathol. (2007) 120:41-46.

[6] French A.T., Knight P.A., Smith W.D., Brown J.K., Craig N.M., Pate J.A., et al., Up-regulation of intelectin in sheep after infection with Teladorsagia circumcincta, Int. J. Parasitol. (2008) 38:467-475.

[7] Gibson A., Lewis A.P., Affleck K., Aitken A.J., Meldrum E., Thompson N., hCLCA1 and mCLCA3 are secreted non-integral membrane proteins and therefore are not ion channels, J. Biol. Chem. (2005) 280:27205-27212.

[8] González L., Anderson I., Deane D., Summers C., Buxton D., Detection of immune system cells in paraffin wax-embedded ovine tissues, J. Comp. Pathol. (2001) 125:41-47.

[9] Halliday A.M., Routledge C.M., Smith S.K., Matthews J.B., Smith W.D., Parasite loss and inhibited development of Teladorsagia circumcincta in relation to the kinetics of the local $\operatorname{IgA}$ response in sheep, Parasite Immunol. (2007) 29:425-434.

[10] Hughes V., Smith S., Garcia-Sanchez A., Sales J., Stevenson K., Proteomic comparison of Mycobacterium avium subspecies paratuberculosis grown in vitro and isolated from clinical cases of ovine paratuberculosis, Microbiology (2007) 153:196-205.

[11] Huntley J.F., Gibson S., Brown D., Smith W.D., Jackson F., Miller H.R., Systemic release of a mast 
cell proteinase following nematode infections in sheep, Parasite Immunol. (1987) 9:603-614.

[12] Huntley J.F., Haig D.M., Irvine J., Inglis L., MacDonald A., Rance A., Moqbel R., Characterisation of ovine mast cells derived from in vitro culture of haemopoietic tissue, Vet. Immunol. Immunopathol. (1992) 32:47-64.

[13] Jackson F., Greer A.W., Huntley J., McAnulty R.W., Bartley D.J., Stanley A., et al., Studies using Teladorsagia circumcincta in an in vitro direct challenge method using abomasal tissue explants, Vet. Parasitol. (2004) 124:73-89.

[14] Knight P.A., Wright S.H., Lawrence C.E., Paterson Y.Y., Miller H.R., Delayed expulsion of the nematode Trichinella spiralis in mice lacking the mucosal mast cell specific granule chymase, mouse mast cell protease 1, J. Exp. Med. (2000) 192:1849-2856.

[15] Komiya T., Tanigawa Y., Hirohashi S., Cloning of the novel gene intelectin, which is expressed in intestinal paneth cells in mice, Biochem. Biophys. Res. Commun. (1998) 251:759-762.

[16] Loewen M.E., Forsyth G.W., Structure and function of CLCA proteins, Physiol. Rev. (2005) 85:1061-1092.

[17] McClure S.J., Emery D.L., Wagland B.M., Jones W.O., A serial study of rejection of Trichostrongylus colubriformis by immune sheep, Int. J. Parasitol. (1992) 22:227-234.

[18] Meeusen E.N., Balic A., Do eosinophils have a role in the killing of helminth parasites?, Parasitol. Today (2000) 16: 95-101.

[19] Miller H.R., Huntley J.F., Protection against nematodes by intestinal mucus, Adv. Exp. Med. Biol. (1982) 144:243-245.

[20] Miller H.R., Jackson F., Newlands G., Appleyard W.T., Immune exclusion, a mechanism of protection against the ovine nematode Haemonchus contortus, Res. Vet. Sci. (1983) 35:357-363.

[21] Miller H.R., The protective mucosal response against gastrointestinal nematodes in ruminants and laboratory animals, Vet. Immunol. Immunopathol. (1984) 6:167-259.

[22] Miyake K., Tanaka T., McNeil P.L., Disruptioninduced mucus secretion: repair and protection, PLoS Biol. (2006) 4:e276.

[23] Mundhenk L., Alfalah M., Elble R.C., Pauli B.U., Naim H.Y., Gruber A.D., Both cleavage products of the mCLCA3 protein are secreted soluble proteins, J. Biol. Chem. (2006) 281:30072-30080.

[24] Pemberton A.D., McAleese S.M., Huntley J.F., Collie D.D., Scudamore C.L., McEuen A.R., et al.,
cDNA sequence of two sheep mast cell tryptases and the differential expression of tryptase and sheep mast cell proteinase-1 in lung, dermis and gastrointestinal tract, Clin. Exp. Allergy (2000) $30: 818-832$

[25] Pemberton A.D., Knight P.A., Wright S.H., Miller H.R.P., Proteomic analysis of mouse jejunal epithelium and its response to infection with the intestinal nematode, Trichinella spiralis, Proteomics (2004) 4:1101-1108.

[26] Sabo-Attwood T., Ramos-Nino M., Bond J., Butnor K.J., Heintz N., Gruber A.D., et al., Gene expression profiles reveal increased mClca3 (Gob5) expression and mucin production in a murine model of asbestos-induced fibrogenesis, Am. J. Pathol. (2005) 167:1243-1256.

[27] Seaton D.S., Jackson F., Smith W.D., Angus K.W., Development of immunity to incoming radiolabelled larvae in lambs continuously infected with Ostertagia circumcincta, Res. Vet. Sci. (1989) 46:241-246

[28] Stear M.J., Strain S., Bishop S.C., How lambs control infection with Ostertagia circumcincta, Vet. Immunol. Immunopathol. (1999) 72:213-218.

[29] Taylor G.K., Goodlett D.R., Rules governing protein identification by mass spectrometry, Rapid Commun. Mass Spectrom. (2005) 19:3420.

[30] Thévenod F., Ion channels in secretory granules of the pancreas and their role in exocytosis and release of secretory proteins, Am. J. Physiol. Cell Physiol. (2002) 283:C651-C672.

[31] Toda M., Tulic M.K., Levitt R.C., Hamid Q., A calcium activated chloride channel (HCLCA1) is strongly related to IL-9 expression and mucus production in bronchial epithelium of patients with asthma, J. Allergy Clin. Immunol. (2002) 109:246-250.

[32] Wu C.C., MacCoss M.J., Shotgun proteomics: tools for the analysis of complex biological systems, Curr. Opin. Mol. Ther. (2002) 4:242-250.

[33] Yasuo M., Fujimoto K., Tanabe T., Yaegashi H., Tsushima K., Takasuna K., et al., Relationship between calcium-activated chloride channel 1 and MUC5AC in goblet cell hyperplasia induced by Interleuhin-13 in human bronchial epithelial cells, Respiration (2006) 73:347-359.

[34] Zhou Y., Dong Q., Louahed J., Dragwa C., Savio D., Huang M., et al., Characterization of a calcium-activated chloride channel as a shared target of Th2 cytokine pathways and its potential involvement in asthma, Am. J. Respir. Cell Mol. Biol. (2001) $25: 486-491$. 